\title{
Exploring Virtual Reality for Quality Immersive Empathy Building Experiences
}

Gareth W. Young, Néill O'Dwyer, and Aljosa Smolic

V-SENSE, School of Computer Science and Statistics, Trinity College Dublin, Ireland.

Cite: Gareth W. Young, Néill O'Dwyer \& Aljosa Smolic (2021): Exploring virtual

reality for quality immersive empathy building experiences, Behaviour \& Information Technology, DOI: 10.1080/0144929X.2021.1993336

\begin{abstract}
Virtual reality (VR) technology presents users with virtual environments that allow them to experience various interactive, immersive, and imaginary experiences. While traditional perspective-taking exercises rely on the participant to imagine a self-other merging process to feel connected with other people (typically using second and third-person narrative perspectives), VR can allow an individual to embody an other through first-person narratives delivered via multimodal - visual, aural, haptic technology-mediated experiences. This process enables users to perceptually and effectively portal into somebody else's body, where they can potentially see, hear, and feel from the point of view of the protagonist and control choices on their behalf in real-time. This article explores the use of VR as an "empathy-making machine" by facilitating perspective-taking and allowing users to experience another person's circumstances. An experiment was performed to compare two different types of perspectivetaking VR applications. Levels of empathy, oneness, and attitudes towards a protagonist or focus group within VR materials were captured. Participants then identified the elements of the VR content that contributed to a quality experience. These measures were used to discuss methodologies and techniques for creating quality empathy-building experiences. The findings of this research will be used to inform future creative technology projects presented in VR.
\end{abstract}

Keywords: virtual reality, empathy, perspective-taking, creative technology

\section{Introduction}

Is virtual reality an empathy-making machine? Today, new technology-mediated experiences are being explored to facilitate innovative ways of using new extended-reality (XR) technologies to promote empathy. XR encompasses multiple software and hardware technologies that enable content creation 
for augmented reality (AR), augmented virtuality (AV), and virtual reality (VR). In 2015, VR was celebrated as an "empathy-making machine" (Milk, 2015) for facilitating perspective-taking and allowing users to experience immersive content from multiple perspectives. In 2021, many different types of empathy-building media are available that vary in their level of immersion and interactivity. Immersion describes how technology can create and sustain an illusion of reality (Slater \& Wilbur, 1997), and interactivity describes the extent to which users can influence the content of the mediated experience in real-time. Immersive and interactive VR experiences simulate environments that users can experience through digitally mediated sensory stimuli (Bailensen, 2018). Immersive virtual environments (IVEs) can perceptually imitate the physical world so that users feel like they are "present" within a virtual experience. This sense of presence within an IVE potentializes a platform for exploring perspectives other than our own (De la Peña et al., 2010). Therefore, VR applications, as IVEs, are being used to present audiences with computer-generated worlds that can be freely interacted with with the sole purpose of increasing empathy.

Empathy is a term that describes an ability to share and understand the emotions of others (Hoffman, 2001). In a medical context, Hojat (2007) defined empathy as "a predominantly cognitive (rather than an emotional) attribute that involves an understanding (rather than feeling) of experiences, concerns, and perspectives of the patient, combined with a capacity to communicate this understanding" (Hojat, 2007; p. 80). Empathy has several profoundly interesting effects upon different elements of prosocial behavior (Batson et al., 1988; Batson et al., 1997). For example, empathy influences intergroup social situations by increasing understanding between groups (Batson \& Ahmed, 2009; Ahn et al., 2013). Together with the related concept of sympathy, these ideas share a long history rooted in the tradition of moral philosophy (Davis, 2018). Empathy and its associated concepts of sympathy and identity have been central to aesthetic discourse since the ancient Greeks, described firstly by Socrates concerning tragic poetry:

"We enjoy it and give ourselves over to it. We suffer along with the hero and take his sufferings seriously. And we praise the one who affects us most in this way as a good poet" - (Plato \& Reeve, 2004: 605d).

\subsection{Perspective-taking}

Researchers have long been interested in understanding how the various affective and cognitive processes of embodying others' experiences can positively impact the observer. Perspective-taking can 
lead the observer to create cognitive portrayals of others that overlap with their representations of self, allowing the perspective-taker to become more "self-like" with the observed person or group (Davis et al., 1996). For example, it has been shown that hearing and witnessing stories of abuse and other sufferings can increase human susceptibility to the internalization of traumatic stress (Babbel, 2012). It has also been observed that a three-way interaction exists between vision, touch, and proprioception that can be exploited in a bodily self-identification context. This phenomenon has been demonstrated in the "rubber hand illusion," where participants have repeatedly reported experiencing a prosthetic limb as belonging to themselves (Bovinick \& Cohen, 1998). Fundamentally, perspective-taking and empathybuilding have for years encompassed many multimodal experiences and presented with innately complex, multidimensional natures (Davis, 1980).

The human mind can imagine various situations that profoundly affect our attitudes and behaviors (Petrova \& Cialdini, 2008). By embodying an avatar within an IVE, perspective-taking has been used to de-bias social judgments and contribute to stereotyping suppression (Galinsky \& Moskowitz, 2000). For example, manifesting White people in a Black virtual body using VR has shown that implicit bias decreased more for those with the Black virtual body than the White (Banakou et al., 2016). Furthermore, Groom et al. (2009) have shown that the effects of avatar embodiment, with features that indicate race, can extend beyond the digital; where people who personified Black avatars within IVEs demonstrated a more significant implicit racial bias outside of the experience than people who embodied a White avatar. This biasing effect has also been extended to other use cases, for example, by reducing stereotypical attitudes towards the elderly (Yee \& Bailenson, 2007).

Moreover, perspective-taking can produce prosocial behaviors and drive outcomes related to social mobility by shifting self-provenance and increasing the perceived overlap between the self and the "other" (Aron et al., 1991, Davis et al., 1996; Cialdini et al., 1997). Measuring self-other overlap identifies feelings of connectedness with other people (oneness) and how close the respondent feels with another person or group (Aron et al., 1992). This effect can be observed as young as five years old (Cameron et al., 2006) and in teens and adults from various backgrounds (Folk et al., 2016; Mashek et al., 2007). The role of self-other overlapping, as feelings of "oneness," in producing prosocial behaviors that have beneficial outcomes to society has implications for media content creation, showing how perspectivetaking can potentially provide a helpful strategy for decreasing stereotype attitudes and influencing how people can benefit others by helping, sharing, donating, co-operating, and volunteering. The effect of 
immersive first-person media on participant attitudes before and after perspective-taking exercises is also reported to build long-term empathy (Herrera et al., 2018).

\subsection{Mediated Empathy}

These approaches to empathy, sympathy, and perspective-taking can explore the concept that personal identity is fundamentally "flexible" (Sinnott, 2017) because aspects of the self can be affected by experiences in the outside world. An empathic response can be evoked in humans when they are presented with the situations of others, whether these others appear in a text (Carrol 2011), television or film (Stadler 2017), audio (Juslin et al. 2010), and other multimedia forms (Batson et al., 1997; Herrera et al., 2018). In this context, technology can be used to raise awareness of the plights of others, influence players' in-game empathy towards non-player characters (NPCs), and increase immersion (Ho $\& \mathrm{Ng}, 2020)$. By digitally recreating human capabilities and allowing others to represent themselves within an experience, virtual realities can lead viewers to accept the illusion of embodying a new corporeal form and accept the potentially different social meaning this new digital body may have (Biocca, 1997).

Likewise, virtual empathic NPC agents within a scene can further enhance immersive experiences by placing themselves into a user's or another agent's emotional situation and respond appropriately (Paiva et al., 2017). Virtual humans have improved understanding of cultural and historical events and behaviors by increasing empathy with the character (Mortara et al., 2014). With the development of "computational empathy," fostering empathy for NPCs through digital means can also increase prosocial responses in human-machine interactions (Paiva et al., 2017). Therefore, perspective-taking can be an effective platform for new insights into how such technologies influence "identity flexibility" for humans and machines.

\subsection{VR Empathy}

A variety of research has been undertaken to show how XR affords "artists the ability to provide new types of imaginary worlds, reproduce specific historical scenarios, [and] apply modern perspectives (e.g., feminism or postcolonialism) to narratives" (O'Dwyer et al., 2020: pp. 202-203). Empathy-driven media can be based on personally experienced circumstances or triggering a moral (positive) reaction that motivates action. Historical empathy, in contrast, can allow users to understand the lived experiences of others at different times in history. Sweeney et al. (2018) discuss the notion of historical empathy as "respect for our predecessors' thoughts and feelings even if we don't share them" (p. 116). This 
approach allows viewers to reinterpret events from their current perspectives and create new empathydriven experiences that will enable audiences to step into another person's shoes and understand their perspective upon a given sequence of events that may have occurred at different times in history. Moreover, these 3D visualizations of historical narratives can be used not only as pedagogical tools to support historical empathy but can highlight how important it is for "understanding humanity's shared story" (Sweeney et al., 2018: p. 116).

Because of these affordances, VR allows users to experience various situations as if they were happening to themselves. In this fashion, VR can be used to create empathy (Milk, 2015). This type of perspective-taking can be seen in several interactive cinematic VR experiences available on the commercial market today; see, for example, the works: Clouds Over Sidra (Arora \& Pousman, 2015), Waves of Grace (Arora \& Milk, 2015), and My Mother's Wing (Arora \& Palitz, 2016). Embodied perspective-taking experiences via VR technology have had observable and transferable effects on reallife, increasing the amount of effort spent helping oneself, others, and meaningfully engaging with nature. Experiments on perspective-taking in VR have explored the impact of computer-generated experiences on eliciting improved feelings of oneness (connectedness with others), empathetic and sympathetic attitudes, and altruism (Ahn et al., 2013).

Furthermore, by allowing users to personify the alternative perceptions of various animal species, a greater sense of embodiment has been recorded by increasing the inclusion of "nature in self" (Ahn et al., 2016). Immersive VR has also shown us a clinical potential for embodying self-compassion via virtual bodies (Falconer et al., 2016). However, research also suggests that perspective-taking can function as a relational amplifier in competitive contexts, leading users to engage in unethical behavior (Pierce et al., 2013). Empathy in IVEs has been of interest to multiple disciplines in the past, and it also presents future VR content creators (artists, filmmakers, etc.) with a new, emergent storytelling platform that effectively promotes empathy towards specific individuals and groups.

Perspective-taking in VR provides researchers with an advantage in terms of the ecological validity of the users' experiences (a measure of how test performance predicts behaviors in real-world settings), since participants each experience the same content and, therefore, do not have to rely on their preexisting schemas or biases (Macrae \& Bodenhausen, 2000; Blascovich et al., 2002). Furthermore, VR provides visual, aural, and tactile stimuli, presenting multimodal information to the body's visual, auditory, and touch systems. Therefore, we can enhance the viewer's immersion via VR technology than traditional, more linear storytelling paradigms (Gaudiosi, 2016). As such, IVEs present audiences with an immersive 
and interactive computer-generated environment that conveys the user's narrative perspective, engrossing them in a digital environment responsive to their actions in real-time.

Different types of VR productions vary in their level of immersion and interactivity. Therefore, in the presented research, we explore two contemporary, novel narrative delivery techniques that provided our users with depictions of "others," allowing them to experience someone else's life. Our experiment demonstrates how digitally mediated empathy-building VR experiences can provide different points of view to encounters created to form connections between other groups of people. Furthermore, we unpack which specific factors of these experiences contribute to the participants' subjective opinions of quality empathy-building experiences.

\subsection{Research Question}

This manuscript explores the phenomenon of VR as an "empathy-making machine" and reports on two public-facing, empathy-driven VR experiences in the wild. The phrase "in-the-wild" describes in situ $\mathrm{HCl}$ research approaches that report user experience phenomena in everyday living (Rogers \& Marshall, 2017). Previous studies have demonstrated that these materials impact the observer in suppressing explicit expressions of bias in controlled laboratory settings.

The following research question was operationalized to assess the efficacy of VR for evoking empathy in the wild: "What are the central dimensions relevant for creating a high-quality empathy-driven experience?" To explore this question, we developed two main hypotheses to contribute new "in-thewild" research findings to the study of VR empathy:

H1. The participants' empathy (H1.1), oneness (H1.2), and attitudes (H1.3) towards a protagonist or group will vary between experiences depending on the content and narrative delivery.

H2. Users can identify essential subjective-quality items from an audiences' perspective by exploring different production methodologies and interaction techniques delivered in the home.

\section{Materials and Methods}

A within-subjects (repeated-measures) study design was implemented. Participants' attitudes towards perspective-taking VR media were focused on two different VR applications, namely Notes on Blindness (Middleton \& Spinney, 2016) and Traveling While Black (Williams, 2019). Imagining what it is like to be someone else can be cogitatively taxing, and care must be taken when designing such studies (Oh et al., 2016); therefore, our approach was to measure our participants' sentiments towards the different focus 
groups in non-laboratory environments and on two separate occasions. Primarily, the study was designed to determine if the stories, production methodologies, and approaches to immersion and interaction applied in each of these experiences could affect the observer's attitudes towards the presented focus group and how close they felt to them. Secondly, we sought to discover which elements of the empathy-driven experiences influenced the participants' impressions of an overall quality empathy-building experience.

To explore and validate these effects of perspective-taking media over time (Herrera et al., 2018), we measured attitudes towards the protagonist or group on three separate occasions. We considered how close the respondent felt with the protagonist or group as a measure of self-other merging (oneness) that each of these experiences provided to determine if the narrative delivery's modality was effective in each scenario (Ahn et al., 2013). Following each VR experience, the participants were asked a series of open-ended questions to explore the defining attributes of a high-quality empathy-building experience.

\subsection{Stimuli (Immersive VR Experiences)}

Traveling While Black (TwB) is a cinematic VR experience that immerses the viewer in a historical narrative describing the restrictions on movement that were foisted upon black Americans, starting with the "Green Book" and the safe spaces and local communities that it created (Williams, 2019). Traveling While Black was directed by documentarian Roger Ross Williams, collaborating with Felix and Paul Studios. The documentary presents a collection of interviews and poetic cinematic recreations that tell harrowing tales of the dangers and humiliations that come packaged with traveling in the USA as a person of color. The viewer shares an intimate series of stories with Ben's Chili Bowl patrons, Washington DC, as they reflect upon their race-related experiences of restricted movement during the mid-to-late-20 $0^{\text {th }}$-century (Felix \& Paul, 2019). The VR experience uses $360^{\circ}$ cinematography to give viewers an immersive cinematic reality (CR) of the topical dangers of being black in America. Unlike computer-generated images (CGI), CR provides the viewer with a detailed, hyper-realistic cinematic quality using high definition $360^{\circ}$ stereoscopic cameras and spatial audio (see Figure 1). This technique furnishes a photorealistic visual close to the mass media market expectations established by television and film. However, the viewpoint is less restrictive because the viewer can look around, albeit from a fixed camera position facilitating three degrees of freedom (3DoF) - tracking rotational motion as pitch, yaw, and roll. Williams describes the perspective-taking experience as follows: 
"If you're not African American, you get to go into a space and be part of a conversation that you probably normally would not be privy to. If you are black, you get to delve deep into that inner trauma that we all carry with us in America as black people... You walk away [and] you feel the sort of empathy and the pain really that black people carry with them in a country that hasn't confronted the reality of racism" - R. R. Williams (McClinton, 2019)

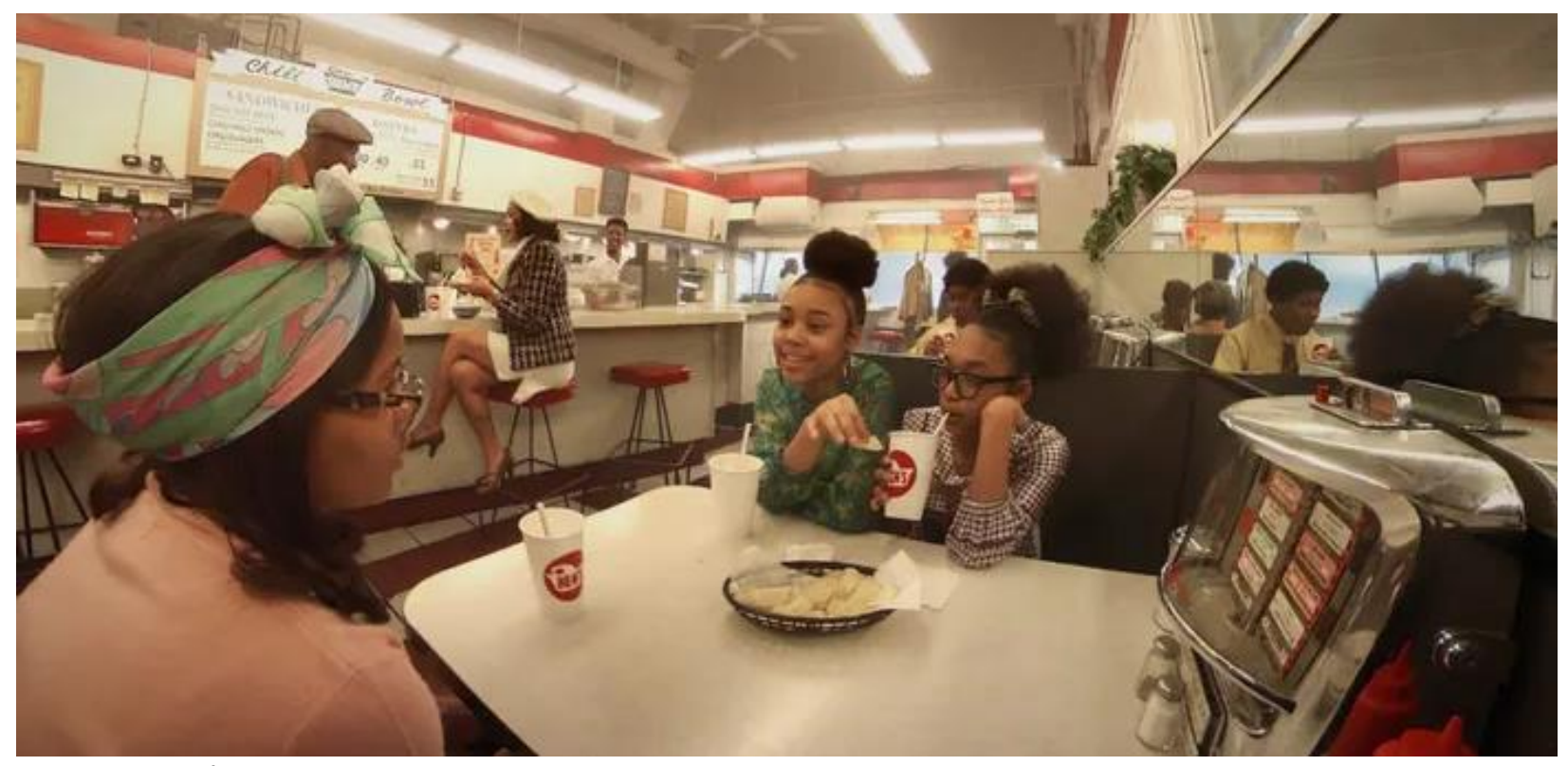

Figure 1: Ben's Chili Bowl in Washington DC; Photograph: Felix \& Paul Studio

(https://www.felixandpaul.com/?travelingwhileblack)

Notes on Blindness (NoB) is an immersive VR experience that retells John Hull's story and his psychosomatic experiences of blindness (Femme Fatale Studio, 2016). This interactive documentary provides six degrees of freedom (6DoF) - complete freedom of movement in 3D space - and applies new forms of storytelling that immerse the viewer in multiple memories inspired and driven by Hull's original audio diaries via binaural audio and 3D CGI animations. The narrator-protagonist relates loss, rebirth, and renewal, defining his journey and coming to terms with blindness. The interactive, expressionistic, and semi-abstract visual content includes CGI representations of water, wind, voices, and music in a 3D IVE. The VR experience allows users to access the world of the narrator via an exploratory user-led first-person perspective, where they are privy to intimate moments of Hull's experiences of a variety of emotions - beauty, fear, anxiety, nostalgia - visualized as multilayered patterns of sound-mapped environments (see Figure 2). By mirroring the narrator's incidents, the 
application uses audiovisual materials that the user can interact with, applying multimedia prompts to explore the virtual world further.

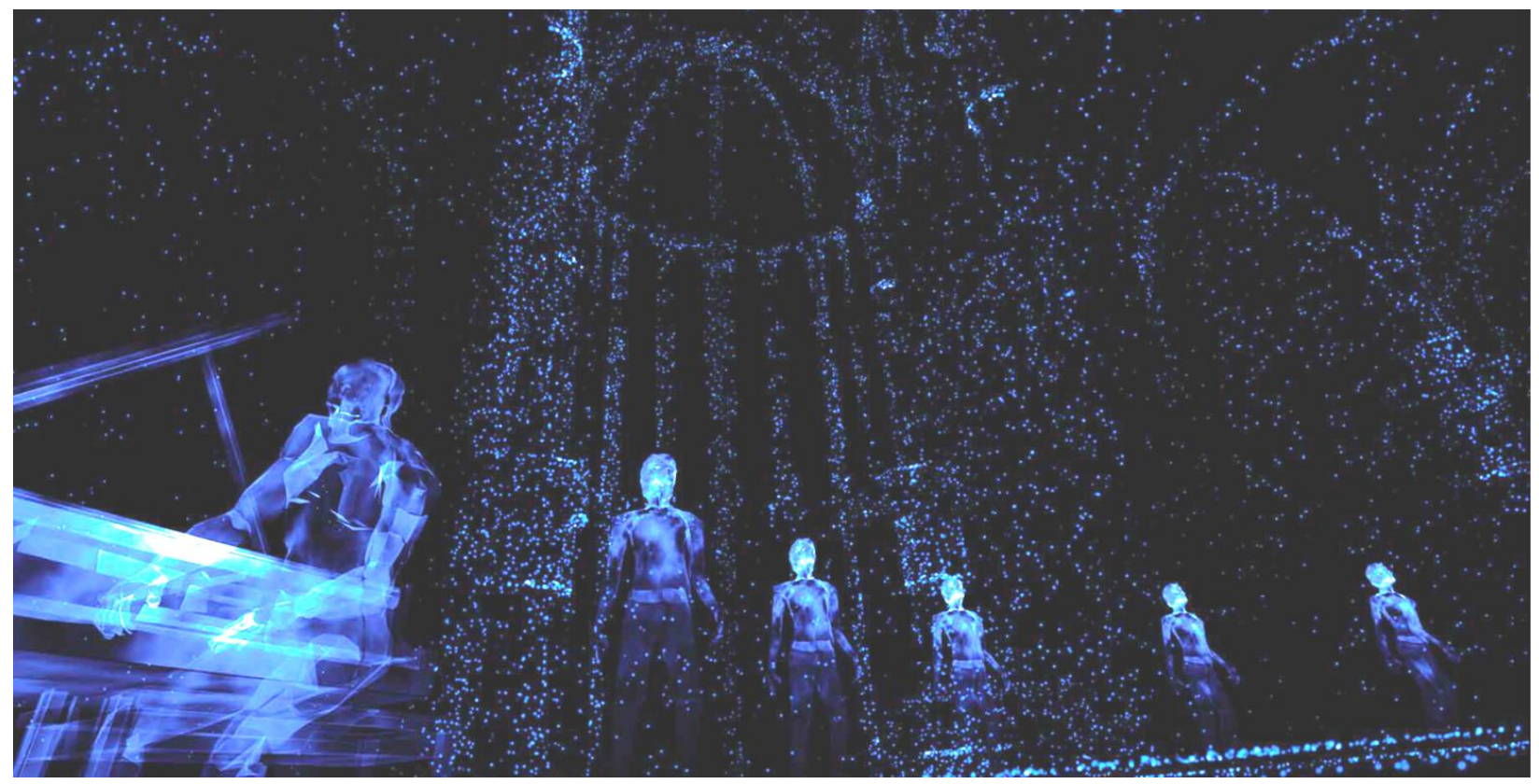

Figure 2: CGI representations of pianist and choir singers; Photograph: Press notes for "Notes on Blindness" (http://www.notesonblindness.co.uk/press/)

\subsection{Recruitment}

Recruitment took place in the Republic of Ireland over 12 months. Members of the public were sought via a social media call and by direct email. The recruitment strategy targeted public members interested in experiencing VR for the first time, current VR users, and VR industry/community stakeholders. Within these groups, contributions were sought from persons with little or no familiarity with VR (novices), users who regularly consume VR content (end-users), and those considered experts (advanced users). To ensure safety and minimize the risk of trauma from entering into the distress of others or issues around feeling connected with other people, which might confuse someone struggling with their own identity, participants were given a research information document that clearly explained the research methodologies involved. The university's Research Ethics Committee (REC) issued ethical approval, and informed consent was received from all participants.

\subsection{Participants}

Initially, 25 participants volunteered for the study; however, five could not complete both experiences due to scheduling conflicts, and their partially completed results were removed from the data. 
Therefore, 20 volunteers fully contributed to the study. The gender identity of the group was 11 Males and 9 Females with an average age of $34.10(S D=3.58)$. Participants self-identified their ethnicity as White Irish $(n=13)$, Asian $(n=4)$, Turkish $(n=2)$, and African Irish $(n=1)$. According to the Irish National Framework of Qualifications (NFQ), the education profile of the cohort consisted of levels 10 ( $n=3), 9$ (n $=11), 8(n=2), 7(n=3)$, and $5(n=1)$. The group's employment according to the professional Nomenclature of Economic Activities (NACE) were Information and Communication Professionals $(n=6)$; Scientific and Technical Activities ( $n=3)$; Administrative and Support Service Activities $(n=3)$; Education $(n=3)$; Arts, Entertainment, and Recreation $(n=2)$; Human Health and Social Work Activities $(n=2)$; and Unemployed $(n=1)$.

\subsection{Experiment Procedure}

It has been observed that previous VR empathy studies have been conducted within controlled laboratory conditions and, as a result, present with limited environmental variance. As an alternative to the prevailing laboratory experimentation paradigm and to capture real-world interactions as they were meant to be consumed, participants were asked to use VR in the privacy of their own homes. Our rationale was that with the increasing ubiquity of personal VR technologies, our experiments were carried out in locations and environments representing current VR use-case scenarios. This approach offered a mode of analysis that yields explicitly actionable and informative contextual knowledge for future content developers (Oulasvirta, 2009). Thus, the methodology involved VR use in the home, workplace, and other environments that afforded no distractions from the presented content but could be considered "natural" for viewing VR applications, according to the experience providers and HMD manufacturer guidelines. Our primary motivations were that there might be causalities in these situations that cannot be staged or reproduced in the laboratory when measuring perspective-taking experiences (Rogers \& Marshall, 2017).

Before arranging remote VR sessions, participants were asked to fill out a demographics questionnaire to identify key user characteristics. This questionnaire included self-reported technology aptitude, knowledge of VR, and expertise using VR via fully labeled 7-point Likert scales (Nielsen, 1994); an Interpersonal Reactivity Index Questionnaire (IRI) measured on 14 fully labeled 5-point scales (1 = Does Not Describe Me Well; 5 = Describes Me Very Well) (Davis, 1980); as well as Beliefs about Empathy (BaE) scales relating to empathic concern and perspective-taking on a fully labeled 6-point Likert scale ( $1=$ strongly disagree; 6 = strongly agree) (Schumann et al., 2014; Herrera et al., 2018). 
A "user cube" was created along the three central dimensions in which users' experience differed: experience with technology in general, with the VR system, and with the task domain. Participants were then grouped as "Novices," "End-users," and "Advanced Users," as described by Nielsen (1994). The IRI measure then defined empathy as the "reactions of one individual to the observed experiences of another" (Davis, 1983: p. 113), and the scales were divided equally between empathetic concern (assessing "other-oriented" feelings of sympathy and concern for unfortunate others) and perspective taking (the tendency to adopt the psychological point of view of others spontaneously). Finally, the BaE captured the participants' feelings of connectedness with other people and social mobility outcomes (Aron et al., 1991). These scales combined were used to describe the individual participants as a population sample group, ensuring no significant differences in empathy beliefs.

A counterbalanced measure was implemented to assign participants to an empathy-building VR experience in advance. At least twenty-four hours preceding the experiment date, participants were asked to complete an online questionnaire adapted from the Attitude Toward Disabled Persons Survey (ATDPS) to determine the extent to which people perceive others as inferior to themselves (Yuker et al., 1966). Sixteen six-point scale items $(+3=$ I agree very much; $-3=$ I disagree very much) were adapted to gauge attitudes toward the main protagonist or group (Yuker et al., 1966; Batson et al., 1997). The word "disabled" was replaced in the questionnaire with more representative terminology, "African American persons" for TwB and "blind persons" for NoB. All questionnaires were delivered, recorded, and stored online via Microsoft Forms and accessed directly via the participants' communication devices (PC, laptop, tablet, mobile phone, etc.).

The experiences were delivered via the Oculus Quest (version 1) VR system. The HMD was hygienically prepared using a UV-C lightbox (Cleanbox CX1) and supplied to each participant in advance. Participants were given a brief description of the experience, such as the focus group and format, a short explanation of the risks of simulation sickness, and a statement alerting them that the VR experience may contain potentially distressing empathy-driven material. The VR system's control mechanisms were explained, and the user interface was demonstrated remotely in advance of the experience on a one-toone basis as required. According to the manufacturer's guidelines, the contributors were asked to make themselves comfortable and don the HMD.

The participant then self-delivered the preselected VR application for the total duration. Immediately following the VR experience, the participants filled out an online questionnaire. First, the participants were asked to report how familiar they were with the production they had just experienced before the 
experiment, on a 7-point Likert scale ( 1 = Unfamiliar; 7 = Extremely Familiar $)$ - "Before viewing the VR experience, how familiar were you with (NoB or TwB)?". Next, two post-task items on 5-point Likert scales were used to measure the success of the participant in taking the perspective of the protagonist or focus group - "Did you feel empathy for the protagonist or group discussed during the session?" (1= Nothing; 5 = Severe) and "How easy or difficult was it for you to experience empathy for the protagonist or group during the session?" (1= Very Easy; 5 = Very Difficult) (Herrera et al., 2018).

An "Inclusion of Other in Self" (IOS) scale was then used to measure "oneness" as to how close or connected the participants felt to the protagonist or focus group during the session (Aron et al., 1992). In this, the participants were asked to choose a picture that best depicted the extent to which they felt connected to or "at one with" the central characters. Respondents chose a pair of circles from seven images with different degrees of overlap. 1 = no overlap; 2 = little overlap; 3 = some overlap; 4 = equal overlap; 5 = strong overlap; 6 = very strong overlap; 7 = most overlap. Finally, the participants were asked to complete the adapted ATDPS questionnaire for a second time to record any immediate changes in their perception of others.

Open-ended questions were then asked relating to the perceived quality of the media experience. These inquiries followed the overall guiding question reported in section 1.5. The following questions operationalized this line of inquiry: First, the participants were asked to describe what they very much liked about their experience, detailing what and why specific criteria were critical. Following this, participants were asked to report what they disliked about the experience, identifying which criteria detracted from the experience and why this was the case. In a third step, the questioning changed to a more abstract level, where participants were asked to report on what features belong to either good or bad multimedia-based empathy-building experiences in general. In the final part, the participants were asked to describe positive and negative experiences of this type of media in any context, including what they thought would be necessary for other media, how they would imagine others' experiences today, and similar inquiries related to everyday media practice in the future.

Twenty-four hours after the experiment, participants were asked to complete the adapted ATDPS questionnaire for the third time to see if the VR content had had any lingering effect on the participants' attitudes. In total, all participants experienced the two separate VR applications over 4 to 6 weeks, depending on their availability. All participants were debriefed once the study had been completed.

\section{Results.}


Empirical data was collected and analyzed. Quantitative data was used descriptively to discover if empathy, oneness, or attitude (over time) changes occurred. Qualitative data were coded and used to enrich and add depth of knowledge to these findings. Depending on the distribution of the variables, we used non-parametric methods (i.e., Kruskal-Wallis, Wilcoxon Signed-Rank Test) or parametric (i.e., ANOVA). We chose 0.05 for the significance level.

\subsection{Population variables}

Data relating to the cohorts' ability to use digital technology $(M=6.15 ; S D=0.93)$, their familiarity or knowledge of virtual reality technology $(M=4.55 ; S D=1.47)$, and their expertise or experience in using virtual reality applications $(M=3.25 ; S D=1.89)$ were captured to identify VR user-types; Novices $(n=6)$, End-users ( $n=7)$, and Advanced users ( $n=7$ ) (Nielsen, 1994), see Table 1.

Table 1: Population Variables

\begin{tabular}{ll|ll|ll} 
& & IRI & & BaE & \\
User-type & $\mathbf{N}$ & Mean & SD & Mean & SD \\
\hline Novices & 6 & 2.58 & 0.40 & 4.42 & 1.25 \\
End-users & 7 & 2.81 & 0.32 & 4.19 & 1.11 \\
Advanced users & 7 & 2.46 & 0.88 & 4.45 & 1.11 \\
\hline Total & 20 & 2.62 & 0.58 & 4.35 & 1.15
\end{tabular}

The IRI data relating to both empathic concern $(M=2.86 ; S D=1.12)$ and perspective-taking $(M=2.62$; $S D=1.21)$ reported a Cronbach's alpha level of 0.87 and 0.66 , respectively. A Kruskal-Wallis Test revealed no statistically significant difference in IRI scores across the three different user-type groups, $X^{2}$ $(2, n=20)=1.66, p=0.44$. The IRI scores ranged from 0.93 to 3.71 and were averaged to create a composite IRI score $(M=2.62 ; S D=0.58)$. The BaE results identified the cohort's implicit beliefs about empathy $(M=4.35 ; S D=1.15)$, with a Cronbach's alpha coefficient of 0.87. A Kruskal-Wallis Test revealed no statistically significant difference in BaE scores across the same user-type groups, $X^{2}(2, n=$ 20) $=0.37, p=0.83$, and were then averaged (see Table1).

\subsection{Outcome Variables}

With no significant differences between population variables, the outcome variables data for user-type were combined for analyses. When describing their familiarity with the empathy-driven VR experiences, the cohort reported that they were "unfamiliar/mostly unfamiliar" for both NoB ( $M=0.4 ; S D=0.99)$ and 
$\operatorname{TwB}(M=0.85 ; S D=1.31)$. Descriptive statistics for post-task responses regarding empathy, oneness, and attitude can be seen in Table 2 .

For NoB, the two empathy check items were highly correlated (Pearson's $r=0.75)$ and averaged (M = 3.9; $S D=1.17)$. For TwB, the two items were also correlated (Pearson's $r=0.70)$ and averaged $(M=4.48$; $S D=0.93)$. Shapiro-Wilk normality tests showed that the distributions of the empathy scores were not normal for either NoB $(W=0.87, p=0.01)$ or TwB $(W=0.64, p<0.00)$. A Wilcoxon Signed-Rank Test was conducted to evaluate the two experiences' impact on participant empathy scores, and there was no statistically significant change in scores between NoB and TwB, $z=-1.72, p=0.09$. The total mean empathy rating for both experiences was 4.19 (SD = 1.09).

Table 2: Descriptive statistics for post-task responses $(n=20)$.

\begin{tabular}{l|llll|llll} 
& NoB & & & & TwB & & \\
Scale & Mean & SD & Min & Max & Mean & SD & Min & Max \\
\hline Empathy & 3.9 & 1.17 & 1 & 5 & 4.48 & 0.93 & 1 & 5 \\
Oneness & 2.85 & 1.93 & 1 & 6 & 3.35 & 1.81 & 1 & 7 \\
Attitude & 0.47 & 0.34 & -0.19 & 0.94 & 1.24 & 0.82 & -0.56 & 2.63
\end{tabular}

The oneness (IOS) measures for NoB showed that the participants felt a "little-to-some" connection with the protagonist during the VR experience $(M=2.85 ; S D=1.93)$. Participants reported a slightly higher connectedness of "some-to-equal" for TwB (M = 3.35; SD = 1.81). Shapiro-Wilk normality tests showed that the distributions of the oneness scores were normal for $\operatorname{TwB}(W=0.93, p=0.13)$ but not for NoB $(\mathrm{W}=0.82, \mathrm{p}<0.00)$. Therefore, a Wilcoxon Signed-Rank Test was conducted to evaluate the two experiences' impact on participant oneness scores, and there was no statistically significant change in scores between NoB and TwB, $z=-0.71, p=0.48$. Thus, average scores were combined $(M=3.10$ and $\mathrm{SD}=1.86)$, showing "some-to-equal" feelings of oneness with the other person or group.

Shapiro-Wilk normality tests showed that the distributions of the attitude scores at $T_{1}$ were normal for $\operatorname{TwB}(W=0.95, p=0.88)$ and NoB $(W=0.92, p=0.11)$. A paired-samples t-test showed that the participants' mean attitudes towards the protagonist or group immediately after the experience were statistically different. There was a statistically significant lower score for $\operatorname{NoB}(M=0.47, S D=0.34)$ to $\operatorname{TwB}(M=1.24, S D=0.82), t(19)=4.61, p<0.00$ (two-tailed). The mean difference in attitude scores was 1.76 , with a $95 \%$ confidence interval ranging from 1.42 to 2.11 . The eta squared statistic (0.1) indicated a moderate to large effect size. 
Participant attitudes were measured on three separate occasions; see Table 3. Shapiro-Wilk normality tests showed that the distributions of the attitude scores at $T_{0}$ and $T_{2}$ were also normal for $T w B\left(T_{0}-W\right.$ $\left.=0.95, p=0.36 ; T_{2}-W=0.98, p=0.86\right)$ and $\operatorname{NoB}\left(T_{0}-W=0.96, p=0.5 ; T_{2}-W=0.97, p=0.7\right) . A$ one-way repeated measures ANOVA was conducted to compare attitude scores at $T_{0}$ ( 24 hours before the intervention), $T_{1}$ (following the intervention), and $T_{2}$ (24 hours after the intervention) for both TwB and NoB. For TwB, the analysis reported that there was no significant effect on participant attitudes over time, Wilks' Lambda $=0.91, F(2,18)=0.69, p=0.51$, multivariate partial eta squared $=0.07$. For NoB, there was a significant effect for time, Wilks' Lambda $=0.39, F(2,18)=14.13, p<.00$, multivariate partial eta squared $=0.61$. A Pairwise Comparisons test was used to compare each of the intervention times. The analysis indicated that the differences between them were significant immediately after the VR experience $\left(T_{1}\right)$ than 24 hours before $\left(T_{0}\right)$ and after $\left(T_{2}\right)$.

Table 3: Participant attitudes 24 hours before the intervention ( $\left.T_{0}\right)$, immediately following the intervention $\left(T_{1}\right)$, and 24 hours after the intervention $\left(T_{2}\right)(n=20)$.

\begin{tabular}{l|ll|ll|ll} 
& $\mathbf{T}_{\mathbf{0}}$ & & $\mathbf{T}_{\mathbf{1}}$ & & $\mathbf{T}_{\mathbf{2}}$ & \\
Experience & Mean & SD & Mean & SD & Mean & SD \\
\hline NoB & 1.19 & 0.80 & 0.47 & 0.39 & 1.26 & 0.90 \\
TwB & 1.43 & 0.46 & 1.23 & 1.82 & 1.22 & 0.74
\end{tabular}

\subsection{Qualitative Data}

A content analysis was used to determine the presence of certain words, themes, or concepts within the qualitative data (Berelson, 1952; Mayring, 2004; Elo et al., 2014). The open-ended responses highlighted potentially important subjective quality benchmark items. These answers were analyzed and used to identify unique quality-related codes. Semantically redundant items were then dropped, resulting in a concentrated list of quality-related elements. Three researchers conducted an affinity diagramming workshop to gather the participants' core themes as collections of similar content, allowing the qualitative data to be grouped. This approach assembled relevant quality data from our users' perspectives for developing a quality item pool targeted towards empathy-driven materials in VR. Refined categories were then created by assigning each sub-level of the affinity diagram to three separate tiers based upon the grouped items' results (see Figure 3 ).

From the qualitative data, coherent thought-units (contiguous statements) were first extracted. Across all open-ended responses, a total of 482 thought-units were identified $(n=20, M: N o B=12.65, S D=$ 
5.31; TwB = 11.45, SD = 4.91). Each thought unit was then reviewed for further division into coherent subunits or single statements (SS), as our observations showed that different quality criteria were revealed within the same thought unit. To reduce this set of subunits, SS were merged and matched for semantic similarity and redundancy within each participant and each experience, resulting in 719 SS (M $=35.95, \mathrm{SD}=14.05$ ) across 14 unique quality criteria. 
Figure 3: Solution of the three-level categorization for a quality empathy-building experience with respective single statements (SS)

\begin{tabular}{|c|c|c|c|c|c|}
\hline Tier 1 & SS & Tier 2 & SS & Tier 3 & SS \\
\hline Human & 373 & & & & \\
\hline \multirow{11}{*}{ Computer (VR) } & \multirow[b]{7}{*}{346} & Psychological & 180 & & \\
\hline & & \multirow[b]{2}{*}{ Imagination } & \multirow[b]{2}{*}{129} & $\begin{array}{l}\text { Empathy } \\
\text { Presence } \\
\text { Exploitation }\end{array}$ & $\begin{array}{l}112 \\
48 \\
20\end{array}$ \\
\hline & & & & & \\
\hline & & \multirow[b]{2}{*}{ User Experience } & \multirow[b]{2}{*}{112} & $\begin{array}{l}\text { Narrative } \\
\text { Production } \\
\text { Fantasy }\end{array}$ & $\begin{array}{l}81 \\
36 \\
12\end{array}$ \\
\hline & & & & & \\
\hline & & \multirow[b]{3}{*}{ Simulation } & \multirow[b]{3}{*}{151} & $\begin{array}{l}\text { Personal Experiences } \\
\text { Accessibility } \\
\text { Usability }\end{array}$ & $\begin{array}{l}65 \\
35 \\
12 \\
\end{array}$ \\
\hline & & & & \multirow[b]{3}{*}{$\begin{array}{l}\text { Interaction } \\
\text { Immersion }\end{array}$} & \multirow[b]{3}{*}{$\begin{array}{l}106 \\
45\end{array}$} \\
\hline & & & & & \\
\hline & & \multirow[b]{2}{*}{ Technology } & \multirow{3}{*}{147} & & \\
\hline & & & & & \\
\hline & & & & $\begin{array}{l}\text { Audio } \\
\text { Visual } \\
\text { Comfort }\end{array}$ & $\begin{array}{l}58 \\
54 \\
35\end{array}$ \\
\hline
\end{tabular}

- Understanding the feelings of others

- The feeling of being inside the virtual world

- Manipulation through indirect, deceptive, or underhanded tactics

- The narrative and creative writing behind the experience

- The making of the overall multimedia experience

- The action of forming new ideas

- The experiences of consuming empathy-building materials

- The accessibility of VR experiences to all people

- How effectiveness, efficiency, and satisfaction were perceived

- The physical interaction between the user and the virtual environment

- The users' mental involvement in the experience due to virtual reality technology

- The spatial audio experience

- The free-viewpoint visual experience

- The physical parts or components of the VR system 


\section{Discussion of Results}

Our study presents a range of attributes that can be explored when creating quality empathy-driven VR content. The experiment studied two different VR experiences to discover if the immersive media production techniques applied in each would encourage greater empathy, oneness, and create a more favorable attitude toward the protagonist or group (H1). Participants then identified which elements were defining characteristics for a quality experience $(\mathrm{H} 2)$.

We knew that some of our user-type cohorts might already be familiar with these productions as visible commercial VR releases. However, as our participants expressed a general unfamiliarity with the experiences; therefore, we can assume that the VR materials were novel. The cohort self-identified as technically competent digital technology users who could be considered novices, end-users, or experts using VR. Participants reported equal empathic concern and perspective-taking levels that demonstrated an average tendency to spontaneously adopt a psychological perspective in everyday life and conveyed a moderate predisposition to experiencing feelings of sympathy or compassion for unfortunate others (Davis, 1983). The BaE scale revealed no significant differences in empathy-based principles, as previous research has demonstrated that participants who believe they can control their empathic responses can exert more empathic effort than those who think they have no control (Schumann et al., 2014).

\subsection{Empathy, Oneness, and Attitudes}

We observed similarly positive empathy and oneness measures for NoB and TwB, rejecting $\mathrm{H} 1.1$ and $\mathrm{H} 1.2$ that supposed the different production approaches ( $\mathrm{CGI}$ and $360^{\circ}$ film) would impact these empathy-building factors. However, our participants' collective attitudes towards the protagonist or group differed significantly between experiences (H1.3). Notably, our cohorts' attitudes changed over time, providing additional information about these perspectives for discussing and supporting $\mathrm{H} 1.3$ for changes in attitude between VR experiences only. For subjective evaluations of a high-quality empathydriven VR experience, the quality of $\mathrm{NoB}$ and TwB was discussed openly to discover the core features of a high-quality empathy-driven VR experience from the audience's perspective in $\mathrm{H} 2$.

Measures of empathy and oneness manifested equally in both empathy-driven experiences, as observed in previous research (Ahn et al., 2013; Herrera et al., 2018), quantifying the degree of the participants' perspective-taking and their perceived character comparison within the applications' presented materials (Maner et al., 2002). We can now also report similar findings for "in the wild" contexts. These 
post-task responses revealed that the modality of the experience, given the variation in production techniques between the two experiences, did not affect the perception of perspective-taking and feeling connected with other people, presenting little evidence to support $\mathrm{H} 1.1$ and $\mathrm{H} 1.2$ - that more significant levels of empathy or perceived oneness will manifest between production and narrative techniques. However, the participants' attitudes toward the different protagonists/groups differed significantly, with lower mean scores for NoB than TwB following the experience $\left(T_{1}\right)$, supporting $H 1.3$.

In summary, these results suggest that both VR production techniques could be considered equally successful in delivering empathy-driven materials, for measures of empathy (H1.1) and oneness (H1.2), but it was participant attitudes towards the protagonist or group that significantly differed depending on the content and narrative delivery of the experience ( $\mathrm{H} 1.3)$.

\subsection{Exploring Effects on Attitudes Over Time}

By measuring attitudes on three separate occasions, we can further understand the effect of these two different VR experiences - in terms of content and narrative delivery - on our participants' attitudes over time, focusing on $\mathrm{H} 1.3$ and the participants' self-reported experiences. For TwB, participants conveyed similarly positive attitudes towards African Americans 24 hours before, immediately after, and 24 hours after the VR intervention. Initially, this rejects H1.3, with no significant changes in attitudes recorded in the data. However, when examining post-experiment open-ended responses, we were able to gain further evidence of subjective external influences on participant attitudes. For example:

"Obviously, this film was made a while ago, but it's a shame all of the stories are still so pertinent to today's events, even the stories from so long ago." — QS51

Moreover, during experiment debriefing, many participants revealed that they were aware of the Black Lives Matter (BLM) movement in the US due to local media coverage and therefore expressed heightened mental alertness regarding the political and social campaigns against police brutality and racially motivated violence in their responses.

The results showed that embodying the experience of being blind for NoB significantly altered the participants' attitudes towards blind persons immediately following the VR experience, supporting H1.3. Yet, 24 hours after the intervention, the participants reported similar attitudes as they had 24 hours before the VR experience. This effect was somewhat contrary to other reports that VR media's effects on participant attitudes have been shown to transfer outside the laboratory and over time (Ahn et al., 2013). 
The measure of attitude over time may have captured the nuanced debate around the differences between sympathetic (reflective) and empathetic (responsive) attitudes, suggesting that $\mathrm{H} 1.3$ requires further investigation focusing on contextual sociopolitical impacts of empathy and sympathy in the media. Adding to the definition of empathy (Hoffman, 2001) - the clarification that (psychosomatically) empathy involves the vicarious sharing of an effect - our measures of empathy are in the responsive or reflexive sphere of human emotion. For Hoffman, empathy is an emotional reflex triggering "the involvement of psychological processes that make a person have feelings that are more congruent with another's situation than with his own" (Hoffman, 2001; p.30). Conversely, sympathy does not necessarily require a congruent emotional alignment with the other's emotion or situation; sympathy is perceived as a discretely different emotion that has, as its object, the other's negative emotion or concern from the perspective of an observer who cares for the other person's well-being (Darwall, 1998). Sympathy consists of a rationalistic process triggering a "feeling [of] sorrow or concern for the distressed or needy other" (Eisenberg, 2000; p.678) and often involves taking active measures towards "alleviating" the situation (Wispé, 1986; p.318; Wispé, 1991). While empathy can lead to sympathy, this is not always the case. Participants seem to have apprehended this shortcoming, warning of the potential superficiality:

"Make[s] people believe they know more than they do about someone's experience." - AW76 or similarly:

\footnotetext{
"With VR, you're stepping into someone else's shoes, so that's a positive. The negative side is people may view it as a gimmick or game and not allow themselves to immerse themselves in the experience fully or not take it seriously." - BN25
}

\subsection{The Central Dimensions for High-quality Empathy-driven Content.}

When asked to provide commentary on the central dimensions relevant to creating a high-quality empathy-driven experience, the participants reported a total of 719 single statements (SS) on two major influences, coded as "Human" (SS = 421) and "Computer (VR)" (SS = 298), see Figure 3. Human factors were SS related to psychological and physiological principles of the experiences of empathy, and Computer (VR) pertained to the technology platform's specific role in the empathy-building process. These results provide data for accepting $\mathrm{H} 2$ by identifying essential subjective-quality items from an audiences' perspective and provide context for our discussions around the impact of $\mathrm{H} 1$ and $\mathrm{H} 2$.

\subsubsection{Human Factors: Psychology $(S S=180)$}


Empathy (SS = 112): The discussion's main focus was understanding others' feelings, bridging the quantitative findings reported in section 4.1. It was expressed that the positive effects of empathybuilding media were that others' stories could be channeled directly rather than indirectly or avoided, as previously observed in other research (Ahn et al., 2013). Using VR as a medium, it was believed that real-life stories could effectively reach more people, and audiences could experience lived histories as first-person experiences, delve into others' lives, and see things from another's perspective. By utilizing first-person perspective-taking capabilities, VR made participants feel more involved in the narrative:

"It made me feel for another person's lived experience." - AW76

The cohort recognized that quality experiences facilitating "other in self" experiences could have favorable and unfavorable consequences. Adverse effects of empathy-building were suggested as making people falsely believe they know the intricacies of someone else's lived experiences.

Furthermore, it was thought that the visceral nature of VR might be overwhelming for sensitive viewers:

"The negative aspect could give you a feeling of despair, where you see all this but couldn't make a change positively." - TH30

Empathy-building experiences require effort and mental engagement. Therefore, audiences had to consciously understand the different characters' motivations and become emotionally attached to the protagonist. However, participants also demonstrated some awareness of the differences between empathy and sympathy:

"After watching this documentary (TwB), I feel like it could make me feel sympathetic rather than empathetic for the community." - TH30

This awareness highlights the importance of understanding the combined impact of $\mathrm{H} 1$ and $\mathrm{H} 2$.

Presence (SS = 48): The participants expressed that they must feel like they themselves existed within the virtual world for a quality experience, as De la Peña et al. (2010) described. By stimulating a familiarity (of senses), the participants thought that they could grasp new and unfamiliar situations better as a simulation of reality or being in the frame as people discussed their lives and surrounded by the story world:

"The parts that affected me most were the times when I felt like sitting at the same table with the protagonist and when they looked into the camera as if they looked at me." - ZE72 
Sharing stories in person allowed the user to feel fully present to the point where they would try to reach out and touch things. However, the ability to get up and walk away also gave them agency to remove themselves physically and mentally, as one participant described:

"I found that the VR experience as a whole was quite distracting (because the surroundings were so interesting to look at and realistic), and often I found myself looking around at the room instead of focusing on what was being said." - XR82

One solution may be to exploit the salient information of light field capture technology to focus narrative resources on regions to attract the users' visual attention (Gill et al., 2021).

Exploitation (SS = 20): Participants commented on how quality experiences could be psychologically manipulative or encourage unethical behavior, as Pierce et al. (2013) noted. Our users were sensitive to and particularly conscious of media propaganda, having experienced media coverage of the 2020 US presidential elections, adding further consideration contextually within the broader critical and philosophical aesthetic theory. As such, participants' concerns pertained to the emotional and political efficacy of VR, or where experiences evoke feelings of sympathy instead of empathy (Wispé, 1986). Although causing viewers to reflect upon and rethink their actions, words, or general attitudes towards others was described positively; this quality could also be used to manipulate emotions and negatively transform society; for example:

"The media are tailored to build empathy and [are] biased, so the producer and consumer need to be extra critical" (sic). - PO75

\subsubsection{Human Factors: Imagination (SS = 129)}

Narrative (SS = 81): Stimulating the audiences' imagination through storytelling was essential in providing high-quality experiences. Intrinsically, narrative and creative storytelling were regarded as fundamentals of excellence. Quality audience experiences revolved around the storyline being delivered, where they could listen and interact with a narrative with implicit control over the pace, duration, and linearity of the media. The stories became more valuable when agency and interaction were also introduced. Engaging with impact, escapism, and emotions helped the participants to become engrossed in the experience and further entertained. It was also suggested that repetitiveness, lack of jeopardy, suspense, or a clear goal would detract from quality materials. It was described that being involved and invested in a storyline was a powerful way to convey others' experiences: 
"With such narratives, we can have powerful stories told in never-before-seen ways. At the same time, the stories open the doors for making entertainment out of abuse..." - BW85

Production (SS = 36): The "making of" the experience was highlighted as an essential quality factor. Attention to design was considered a required quality to provide an effective platform for audience engagement. However, a well-produced VR experience could also be downgraded if a "lack of passion" was perceived while creating the content. Quality production-value was also seen as crucial for tailoring the design of an experience and adapting the medium to the subject matter and context as one participant realized:

"It is also good, especially for movies, a little less so for games, that the experience is tailored for the viewer by directors." - OD62

Fantasy (SS = 12): The audience's mind was also considered a quality component for engaging in new ideas through fiction. If the audience could imagine themselves present, they could also internally portray other realities (Petrova \& Cialdini, 2008), with multimodal audiovisual stimuli being the most effective for bridging the physical world with the imaginary (Young et al., 2018). Creativity and imagination were relevant in this context for continuing the story or imagining alternative scenarios.

\subsubsection{Human Factors: User Experience $(S S=112)$}

Personal Experiences (SS = 65): The participants believed that having the device to themselves was a "beautiful thing" as people rarely experience others' lives in such an intimate manner. As such, user experience was suggested as a quality item for consideration. To hear and relive open accounts provided an insightful and relatable narrative that developed a human connection, a particularly poignant quality during the isolation of COVID-19 lockdown; this was described as such:

"Multimedia experiences are available for the common person, and they allow you to be comfortable in your personal space." - LM16

Participants enjoyed the experience of seeing and controlling their virtual point of view and exploring their digital environment in real-time. Once they had a feel for the endeavor, they could focus and watch without distractions. However, solo VR raised issues that may detract from the experience by not making their impressions immediately available for perceiving and acting upon others. It was expressed that using XR in isolation (as with many computer-driven narratives) fails to take advantage of the 'feedback loop of emotional contagion' (Mee cited in O'Dwyer 2021: p.158) experienced by communal 
audiences in conventional theatre and cinematic settings, so it runs the risk of becoming tedious or unpleasant once the novelty wears off. Consequently, designing a system for expressing and sharing personal experiences and creating a world for others to perceive and develop would be advantageous (Mentis et al., 2014).

Accessibility (SS = 35): Participants commented on the current resurgence of VR technology (Evans, 2018). It was believed that the platform was more widely available, and they could see themselves using it at home and in their work. The cohort thought VR could operate not only as an extension of the cinematic screen but as a workplace monitor, thus becoming more familiar to the public and gaining more users. However, it was acknowledged that current access to the equipment was limited and that it is currently much cheaper and easier to access a book for entertainment purposes. Furthermore, it was felt that some people might not be inclined to use VR often as an alternative to traditional media, targeting their comments on digital literacy and distributable media sources.

Usability (SS = 12): The participants provided some personal insight into the role of the interface's quality, as designed with effectiveness, efficiency, and satisfaction in mind. The focus of these comments was on the ease of use or consistency in creating the VR interactions they experienced. Specifically, the cohort provided reports on user controls for orientation, reading captions, difficulties picking up the controllers, and figuring out how to use the HMD and what actions they impacted upon undertaking each VR experience.

\subsubsection{Computer (VR): Simulation (SS = 151)}

Interaction (SS = 106): Regarding interactivity, participants raised several crucial issues. Interactivity in VR facilitates a seamless, user-centric movement in 3D space, providing an opportunity for non-linearity and the chance for dynamic media content consumption. Furthermore, by addressing empathy in humans and embuing virtual characters with agency, adopting empathetic agents within an experience may also create a more empathic interaction with the narrative (Paiva et al., 2017). It was expressed that interactivity raised the audience above passive, consumptive spectators. At the most basic level, the user-controlled their perspective, allowing them to explore the virtual space and potentially interact with the virtual world around them; for example, when discussing TwB, one participant noted:

"This was a movie, so I understand that this feeling is about wanting a more interactive experience [in VR]." - BW85 
In TwB, having only three degrees of freedom made the participants uneasy and occasionally nauseous as they could not see over obstacles or around bends by moving their heads. Although the photorealistic settings were described as "delightful to explore by looking around," being stuck in one spot within the immersive environment was labeled "quite annoying" compared with NoB. The VR medium innately facilitates physical interaction; therefore, the participants felt that they should also have the ability to affect the world in other ways:

"If the VR experience tends to be non-interactive and TV-like, I guess I'd prefer watching the content on TV than on an HMD. I think it makes sense to watch movies or TV series from the viewpoints decided by a director who knows how to forge narrative using pictures." - JR85

It was also expressed that audiences would rate an experience poorly if it required "too much" control or action. In particular, for NoB, when the interactions became too complicated, the experience was described as overwhelming. On the one hand, moving freely and without physical constraints within the VR environment was considered a good feature, and on the other, too many control features detracted from the overall experience. Therefore, it was generally believed that quality experiences should have a balanced approach to agency and interaction.

Immersion (SS = 45): The users' mental involvement helped them become immersed in the experience as facilitated by the platform. It was remarked that other media were not as captivating as VR and that the technology was, by self-definition, immersive. When enveloped in the virtual world, participants expressed enjoyment of the various idiosyncrasies of VR over TV or cinema, like the potential to get lost within the story world; for example:

"Immersion is one of the things that is needed for good VR experiences. For this, they do not have to have perfect graphics. That would be an additional step towards complete immersion." $-J R 85$

When discussing TwB, the additional detail provided by the 360 camera improved the participants' perceptions of immersion as it offered a slightly less discernible difference in quality from other filmbased media. Although it was felt that TwB could have been told through traditional (filmic) media formats, it was also considered more effective in VR because it cuts off ambient phenomena that could distract from the content; for example:

"When watching a movie or TV at home, you could easily get distracted. You need to be engaged in the content to stay focused and finish it without distractions around. Using a device 
close to your eyes and ears helps provide an immersive experience that keeps you engaged." TH30

\subsubsection{Computer (VR): Technology (SS = 147)}

Audio (SS = 58): The cohort enjoyed looking around and finding sound sources regarding spatial audio quality. The directionality of environmental audio was considered an essential and distinguishable factor for VR technology over more traditional stereo formats; for example:

"The sound was captivating when listening to the rain and wind and the choir." - BN25

Although NoB was the main focus of this discussion topic, TwB was also praised for its depth of auditory field, particularly the natural ambiance and reverberation of the environment.

Visual (SS = 54): The hardware's visual quality was considered a significant quality factor, focussing on sharp images, vibrant color palettes, aesthetics, fidelity, and animation versus film. The cinematography was considered more important for VR than TV or cinema, and the combined use of audiovisual materials was supposed highly advantageous for a quality experience; for example:

"Although the animations are nice, I generally tend to focus on the visual quality (e.g., the depiction of the world)" - JR85

And

"The visuals shown go well with the voice in the recorded tapes, and that made it a good experience. "- LM16

In this way, it was possible to guide the viewer's attention (Gill et al., 2021) beyond a purely visually stunning experience via consistent visual cues and poignant interaction triggers.

Comfort (SS = 35): The VR system's physical elements were highlighted to influence the experience's quality. These included references to the technology's ergonomics, wearing the HMD correctly, fatigue, and being conscious of or uncomfortable wearing the equipment. Participants reported that their experiences were initially interrupted by the placement or wearing of the headset and the constant shifting in position. Moreover, it was felt that the current technology was unsuitable for prolonged use or for people who wear glasses; for example:

"The technology feels clunky; it can create a barrier between the user and the virtual world." FY66 
However, the hardware's multimodality was considered a positive quality factor as users acknowledged that VR could be used to more effectively engage the senses than when watching TV or movies at home.

\subsection{Constraints of the Study and Future Work}

While consuming empathy-driven media in VR has significantly impacted participants in controlled laboratory settings, measuring empathy in the home reduces the rigor and control of the experiment procedure. However, our experiments show that commercial VR and public-facing projects can generate compassion, oneness, and alter user attitudes in the home. However, the broader implications of $\mathrm{H} 1$ and $\mathrm{H} 2$ when exploring empathy-driven media via VR can potentially add further discourse to the transition of empathy (reflexive) to sympathy (reflective) using aesthetic theory and practice, for example, from the fields of film theory and/or performance studies to try to explain the results obtained in the experiment and the effects on attitudes over time.

Moreover, we have demonstrated how a media's impact is influenced by social issues surrounding the materials' focus groups, suggesting that attention should also be placed on the audience's sociopolitical, cultural, and economic perspectives when measuring empathy. Cultural context and media coverage can influence empathy-building, and awareness of dominant sociocultural, political subjectivities should have also been captured, for example, racial biasing during mass protests (Banakou et al., 2016), homelessness during a housing crisis (Herrera et al., 2018), or veganism during a food crisis (Ahn et al., 2016).

The findings reported from our qualitative study constitute promising results regarding the role of quality content and technology in empathy-making in VR experiences. The factors identified from our three-tiered quality analysis (see Figure 3) will guide future VR empathy content creation and usercentered experiments, focusing on the holistic experiences of the user. Moreover, theoretical and game design implications should also be discussed further. Furthermore, we can potentially gain additional knowledge from the analysis of such works from an artistic perspective, where the artwork's contemporary, personal, cultural, and formal context can be explored in tandem with traditional $\mathrm{HCl}$ evaluation methodologies (O'Dwyer et al., 2020). This approach will provide a foundation for understanding the overall human-technology quality requirements of empathy-driven experiences presented in VR.

Empathy in media research has a long and fascinating history, where the actions and emotions of the protagonist have an observable effect on an audience (Zillmann \& Cantor, 1977). As such, in the 
presented study, we do not provide a baseline measurement. We felt that it would be too timeconsuming for our participants (although possible, given the excellent quality film material available, at least for NoB). However, the discussion of results concerning human and computer (VR) dimensions of the conducted study supports earlier reported findings. For example, the role of the imagination, as a necessary criterion for empathy to occur (Tamborini et al., 1990), has been remarked upon for other media types, such as film. Likewise, it has been previously observed that as humans, we are naturally predisposed to express compassion towards a protagonist in film media, enhancing the "depth of emotion" the audience experiences (Cantor, 2004).

\section{Conclusion}

In this manuscript, we explored the use of empathy-building VR media in the home, capturing our participants' empathy, oneness, and attitudes following a commercial VR experience in a domestic environment. These VR experiences focused on disadvantaged subject groups and used two unique media production techniques (CGI and $360^{\circ}$ videos). Overall, the cohort experienced empathy and oneness and enjoyed using VR at home as it delivered a sense of understanding in a way that other mainstream media could not. The data collected also provides a foundation for reporting the subjective components of a high-quality empathy-driven VR experience. The participants offered further details on their encounters with other empathy media and their quality expectations for future empathy-driven VR experiences. The practice of consuming quality empathy materials in VR created a 3-tier hierarchy of perceived quality (see Figure 3). The participants discussed human factors concerning the psychological effects of perspective-taking, the role of stimulating the viewers' imagination, and the users' overall understanding of the presented materials. These findings can be explored in new media productions for VR storytelling and capture the perceived quality of empathy materials delivered via VR.

\section{Acknowledgments}

This publication has emanated from research conducted with the financial support of Science Foundation Ireland (SFI) under Grant Number 15/RP/2776.

\section{References}

Ahn, S. J., Bostick, J., Ogle, E., Nowak, K. L., McGillicuddy, K. T., \& Bailenson, J. N. (2016). Experiencing nature: Embodying animals in immersive virtual environments increases inclusion of nature in self and involvement with nature. Journal of Computer-Mediated Communication, 21(6), 399-419. 
Ahn, S. J., Le, A. M. T., \& Bailenson, J. (2013). The effect of embodied experiences on self-other merging, attitude, and helping behavior. Media Psychology, 16(1), 7-38.

Aron, A., Aron, E. N., Tudor, M., \& Nelson, G. (1991). Close relationships as including other in the self. Journal of Personality and Social Psychology, 60(2), 241-253.

Aron, A., Aron, E. N., \& Smollan, D. (1992). Inclusion of other in the self scale and the structure of interpersonal closeness. Journal of personality and social psychology, 63(4), 596.

Arora, G. \& Milk, C. (Directors) (2015). Waves of Grace [Cinematic VR]. USA: VRSE.works

Arora, G. \& Palitz, A. (Directors) (2016). My Mother's Wing [Cinematic VR]. USA: Within.

Arora, G. \& Pousman, B. (Directors) (2015). Clouds over Sidra [Cinematic VR]. Canada: The Sidra Project.

Babbel, S. (2012). Compassion Fatigue: Bodily symptoms of empathy. Psychology Today, retrieved from https://www.psychologytoday.com/ie/blog/somatic-psychology/201207/compassion-fatigue on Oct 9, 2019.

Bailenson, J. (2018). Experience on Demand: What virtual reality is, how it works, and what it can do. WW Norton \& Company.

Banakou, D., Hanumanthu, P. D., \& Slater, M. (2016). Virtual embodiment of white people in a black virtual body leads to a sustained reduction in their implicit racial bias. Frontiers in human neuroscience, $10,601$.

Batson, C. D., \& Ahmad, N. Y. (2009). Using empathy to improve intergroup attitudes and relations. Social issues and policy review, 3(1), 141-177.

Batson, C. D., Dyck, J. L., Brandt, J. R., Batson, J. G., Powell, A. L., McMaster, M. R., \& Griffitt, C. (1988). Five studies testing two new egoistic alternatives to the empathy-altruism hypothesis. Journal of personality and social psychology, 55(1), 52.

Batson, C. D., Polycarpou, M. P., Harmon-Jones, E., Imhoff, H. J., Mitchener, E. C., Bednar, L. L., ... \& Highberger, L. (1997). Empathy and attitudes: Can feeling for a member of a stigmatized group improve feelings toward the group?. Journal of personality and social psychology, 72(1), 105.

Berelson, B. (1952). Content Analysis in Communication Research. Free Press. 
Biocca, F. (1997). The cyborg's dilemma: Progressive embodiment in virtual environments. Journal of computer-mediated communication, 3(2), JCMC324.

Blascovich, J., Loomis, J., Beall, A. C., Swinth, K. R., Hoyt, C. L., \& Bailenson, J. N. (2002). Immersive virtual environment technology as a methodological tool for social psychology. Psychological Inquiry, 13(2), 103-124.

Botvinick, M., \& Cohen, J. (1998). Rubber hands 'feel' touch that eyes see. Nature, 391(6669), 756-756.

Carroll, N. (2011) "On Some Affective Relations between Audiences and the Characters in Popular Fictions," in A. Coplan and P. Goldie (eds.) Empathy: Philosophical and Psychological Perspectives, Oxford: Oxford University Press, 162-84.

Cameron, L., Rutland, A., Brown, R., \& Douch, R. (2006). Changing children's intergroup attitudes toward refugees: Testing different models of extended contact. Child Development, 77(5), 1208-1219.

Cantor, J. (2004). "I'Il never have a clown in my house"-why movie horror lives on. Poetics Today, 25(2), 283-304.

Cialdini, R. B., Brown, S. L., Lewis, B. P., Luce, C., \& Neuberg, S. L. (1997). Reinterpreting the empathyaltruism relationship: When one into one equals oneness. Journal of personality and social psychology, 73(3), 481.

Darwall, Stephen. (1998). "Empathy, Sympathy, Care," Philosophical Studies, 89: 261-282.

Davis, M. H. (1980). A multidimensional approach to individual differences in empathy. JSAS Catalog of Selected Documents in Psychology, 1980, 10, p. 85.

Davis, M. H. (1983). Measuring individual differences in empathy: Evidence for a multidimensional approach. Journal of personality and social psychology, 44(1), 113.

Davis, M. H. (2018). Empathy: A social psychological approach. Routledge.

Davis, M. H., Conklin, L., Smith, A., \& Luce, C. (1996). Effect of perspective taking on the cognitive representation of persons: a merging of self and other. Journal of personality and social psychology, 70(4), 713. 
De la Peña, N., Weil, P., Llobera, J., Giannopoulos, E., Pomés, A., Spanlang, B., ... \& Slater, M. (2010). Immersive journalism: immersive virtual reality for the first-person experience of news. Presence: Teleoperators and virtual environments, 19(4), 291-301.

Eisenberg, N., (2000). "Empathy and Sympathy," M. Lewis and J.M. Haviland-Jones (eds.), Handbook of Emotions, New York/London: Guilford Press, 677-691.

Elo, S., Kääriäinen, M., Kanste, O., Pölkki, T., Utriainen, K., \& Kyngäs, H. (2014). Qualitative Content Analysis: A focus on trustworthiness. SAGE open, 4(1), 2158244014522633.

Evans, L. (2018). The re-emergence of virtual reality. Routledge.

Falconer, C. J., Rovira, A., King, J. A., Gilbert, P., Antley, A., Fearon, P., ... \& Brewin, C. R. (2016). Embodying self-compassion within virtual reality and its effects on patients with depression. BJPsych Open, 2(1), 74-80.

Felix \& Paul (2019). Traveling While Black [Website]. Felix \& Paul Studios, retrieved from https://www.felixandpaul.com/?projects/twb on Nov 4, 2019.

Femme Fatale Studio (2016). Notes on Blindness VR experience. Retrieved from http://notesonblindness.arte.tv/en/vr on Nov 5, 2019.

Folk, J. B., Mashek, D., Tangney, J., Stuewig, J., \& Moore, K. E. (2016). Connectedness to the criminal community and the community at large predicts 1-year post-release outcomes among felony offenders. European journal of social psychology, 46(3), 341-355.

Galinsky, A. D., \& Moskowitz, G. B. (2000). Perspective-taking: decreasing stereotype expression, stereotype accessibility, and in-group favoritism. Journal of personality and social psychology, 78(4), 708. Gaudiosi, J. (2016). UN Uses Virtual Reality to Raise Awareness and Money. Fortune: Tech article retrieved from https://fortune.com/2016/04/18/un-uses-virtual-reality-to-raise-awareness-and-money/ on Oct 9, 2019.

Gill, A., Zerman, E., Alain, M., Le Pendu, M., \& Smolic, A. (2021, June). Focus Guided Light Field Saliency Estimation. In 2021 13th International Conference on Quality of Multimedia Experience (QoMEX) (pp. 213-218). IEEE.

Groom, V., Bailenson, J. N., \& Nass, C. (2009). The influence of racial embodiment on racial bias in immersive virtual environments. Social Influence, 4(3), 231-248. 
Herrera, F., Bailenson, J., Weisz, E., Ogle, E., \& Zaki, J. (2018). Building long-term empathy: A large-scale comparison of traditional and virtual reality perspective-taking. PloS one, 13(10), e0204494.

Ho, J. C., \& Ng, R. (2020). Perspective-Taking of Non-Player Characters in Prosocial Virtual Reality Games: Effects on Closeness, Empathy, and Game Immersion. Behaviour \& Information Technology, 1-14.

Hoffman, M. L. (2001). Empathy and moral development: Implications for caring and justice. Cambridge: Cambridge University Press.

Hojat, M. (2007). Empathy in patient care: antecedents, development, measurement, and outcomes. Springer Science \& Business Media.

Hume, D, Selby-Bigge, L. A and Nidditch P. H. (1739-40 [1978]). A Treatise of Human Nature, Oxford: Oxford University Press.

Juslin, P. et al. 2010; "How Does Music Evoke Emotions?" in Patrik Juslin \& John Sloboda eds., Handbook of Music and Emotion: Theory, Research, Applications, New York: Oxford University Press, 605- 42.

Macrae, C. N., \& Bodenhausen, G. V. (2000). Social cognition: Thinking categorically about others. Annual review of psychology, 51(1), 93-120.

Maner, J. K., Luce, C. L., Neuberg, S. L., Cialdini, R. B., Brown, S., \& Sagarin, B. J. (2002). The effects of perspective-taking on motivations for helping: Still no evidence for altruism. Personality and social psychology bulletin, 28(11), 1601-1610.

Mayring, P. (2004). Qualitative content analysis. A companion to qualitative research, 1(2), 159-176.

Mashek, D., Cannaday, L. W., \& Tangney, J. P. (2007). Inclusion of community in self scale: A single-item pictorial measure of community connectedness. Journal of Community Psychology, 35(2), 257-275.

McClinton D. (Sep 2019). Traveling While Black: Behind the eye-opening VR documentary on racism in America. Retrieved from https://www.theguardian.com/tv-and-radio/2019/sep/02/traveling-whileblack-behind-the-eye-opening-vr-documentary-on-racism-in-america on Nov 5, 2019.

Mentis, H. M., Laaksolahti, J., \& Höök, K. (2014). My self and you: Tension in bodily sharing of experience. ACM Transactions on Computer-Human Interaction (TOCHI), 21(4), 1-26.

Middleton, P. \& Spinney, J. (Directors) (2016). Notes on Blindness [Interactive 3D Animation]. UK: Archer's Mark. 
Milk, C. (2015). How virtual reality can create the ultimate empathy machine. TED Talk (10:26), retrieved from

https://www.ted.com/talks/chris milk how virtual reality can create the ultimate empathy machin e?language=en on Oct 9, 2019.

Mortara, M., Catalano, C. E., Bellotti, F., Fiucci, G., Houry-Panchetti, M., \& Petridis, P. (2014). Learning cultural heritage by serious games. Journal of Cultural Heritage, 15(3), 318-325.

Nielsen, J. (1994). Usability engineering. Amsterdam: Elsevier.

O'Dwyer, N., Young, G. W., Johnson, N., Zerman, E., \& Smolic, A. (2020, July). Mixed Reality and Volumetric Video in Cultural Heritage: Expert Opinions on Augmented and Virtual Reality. In International Conference on Human-Computer Interaction (pp. 195-214). Springer, Cham.

Oh, S. Y., Shriram, K., Laha, B., Baughman, S., Ogle, E., \& Bailenson, J. (2016). Immersion at scale: Researcher's guide to ecologically valid mobile experiments. In 2016 IEEE Virtual Reality (VR) (pp. 249250). IEEE.

Oulasvirta, A. (2009). Field experiments in $\mathrm{HCl}$ : promises and challenges. In Future interaction design (pp. 87-116). Springer, London.

Paiva, A., Leite, I., Boukricha, H., \& Wachsmuth, I. (2017). Empathy in virtual agents and robots: A survey. ACM Transactions on Interactive Intelligent Systems (TiiS), 7(3), 1-40.

Petrova, P. K., \& Cialdini, R. B. (2008). Evoking The Imagination as a Strategy of Influence. In Haugtvedt, C. P., Herr, P. M. \& Kardes F. R. (Eds.), Handbook of Consumer Psychology. New York: Psychology Press, pp. 505-524.

Pierce, J. R., Kilduff, G. J., Galinsky, A. D., \& Sivanathan, N. (2013). From glue to gasoline: How competition turns perspective takers unethical. Psychological science, 24(10), 1986-1994.

Plato, and Reeve, C. D. C. (2004). Republic. Indianapolis: Hackett Pub. Co.

Rogers, Y., \& Marshall, P. (2017). Research in the Wild. Synthesis Lectures on Human-Centered Informatics, 10(3), i-97.

Schumann, K., Zaki, J., \& Dweck, C. S. (2014). Addressing the empathy deficit: Beliefs about the malleability of empathy predict effortful responses when empathy is challenging. Journal of personality and social psychology, 107(3), 475. 
Shaw, P. (2006). The Sublime. London; New York: Routledge.

Sinnott, J. D. (2017). Identity flexibility during adulthood. Springer Verlag.

Slater, M., \& Wilbur, S. (1997). A framework for immersive virtual environments (FIVE): Speculations on the role of presence in virtual environments. Presence: Teleoperators \& Virtual Environments, 6(6), 603616.

Stadler, J. (2017). "Empathy in Film." In The Routledge Handbook of Philosophy of Empathy, edited by Heidi Maibom, 1st ed., 317-26. New York : Routledge.

Sweeney, S. K., Newbill, P., Ogle, T., \& Terry, K. (2018). Using augmented reality and virtual environments in historic places to scaffold historical empathy. TechTrends, 62(1), 114-118.

Tamborini, R., Stiff, J., \& Heidel, C. (1990). Reacting to graphic horror: A model of empathy and emotional behavior. Communication Research, 17(5), 616-640.

Titchener, E. B. (1909). Lectures on the Experimental Psychology of the Thought-Processes. New York: Macmillan.

Williams, R. R., (Director) (2019). Traveling While Black [Cinematic VR]. Canada: Felix \& Paul Studios. Wispé, L. (1986). The distinction between sympathy and empathy: To call forth a concept, a word is needed. Journal of personality and social psychology, 50(2), 314-321.

Wispé, L. (1991). The Psychology of Sympathy, New York/London: Plenum Press.

Yee, N., \& Bailenson, J. (2007). The Proteus effect: The effect of transformed self-representation on behavior. Human communication research, 33(3), 271-290.

Young, G. W., Mannion, S., and Wentworth, S. (2018). Evoking Places from Spaces: The application of Multimodal Narrative Techniques in the Creation of "U - Modified." In the 15th Sound and Music Computing Conference (SMC2018), Limassol, Cyprus.

Yuker, H. E., Block, J. R., \& Younng, J. H. (1966). The measurement of attitudes toward disabled persons. New York: Human Resources Center.

Zillman, D., \& Cantor, J. R. (1977). Affective responses to the emotions of a protagonist. Journal of Experimental Social Psychology, 13(2), 155-165. 